\title{
Twigs, Sequences and the Temporal Constitution of Predicates
}

\author{
Sandro Zucchi \\ Cornell University
}

\author{
Michael White \\ CoGenTex, Inc.
}

\section{Krifka on Aspectual Composition}

Krifka $(1986,1989,1992)$ has proposed an explicit model-theoretic account of the influence of the reference types of NPs (mass nouns, count nouns, plurals, etc.) on the temporal constitution of verbal predicates (activities, accomplishments and achievements). This influence is illustrated by the fact that, while the sentences in (2) are perfectly natural, the sentences in (1) are not acceptable, unless they are understood iteratively:
a. ?? John found a flea for an hour
b. ?? John wrote a letter for an hour
a. John found fleas for an hour
b. John drank milk for an hour
c. John wrote letters for an hour

Krifka's account is based on the following assumptions. The domain of entities contains both objects and events. An entity may be joined with another entity to form a new plural entity (the model structure of individual objects and events is a lattice, as in Link (1983)). Once the domain of entities is structured in this way, we can define the notions quantized predicate and cumulative predicate as follows:

$\forall \mathrm{P}[\mathrm{QUA}(\mathrm{P}) \leftrightarrow \forall \mathrm{x} \forall \mathrm{y}[(\mathrm{P}(\mathrm{x}) \wedge \mathrm{P}(\mathrm{y})) \rightarrow \neg \mathrm{y} \subset \mathrm{x}]]$

|a predicate $P$ has quantized reference iff no $P$-entity can be a proper subpart of a P-entity]

$\forall \mathrm{P} \mid \mathrm{CUM}(\mathrm{P}) \leftrightarrow \forall \mathrm{x} \forall \mathrm{y}[(\mathrm{P}(\mathrm{x}) \wedge \mathrm{P}(\mathrm{y})) \rightarrow \mathrm{P}(\mathrm{x} \cup \mathrm{y})]]$

|a predicate $P$ has cumulative reference iff for every $P$-entity $x$ and $y$, the sum of $x$ and $y$ is still a P-entityl

Krifka's claim is that the distribution of for-adverbs follows from Assumption 1:

A 1. The domain of application of for-adverbs is restricted to non-quantized event predicates.

In order to derive facts (1)-(2) from this assumption, one needs to provide a compositional semantics by which "find a flea" and "write a letter," unlike "find fleas," drink milk" and "write letters," turn out to be quantized. To see how this task is accomplished by Krifka, let 's consider some of the translations given in Krifka ( 1992) for different NP types and different predicate types:

\begin{tabular}{|c|c|c|c|}
\hline write & |subj, ag||obj, pat| & $\Rightarrow$ & $\lambda$ e|write ${ }^{\circ}(\mathrm{e}) \mid$ \\
\hline find & |subj, ag||obj, pat] & $\Rightarrow$ & $\lambda$ e|find'(e)| \\
\hline dri & |subj, ag||obj, pat| & $\Rightarrow$ & $\left.\lambda e \mid d r i n k^{\prime}(e)\right]$ \\
\hline pus & |subj, ag\|obj, pat| & $\Rightarrow$ & $\lambda e \mid p u s h '(e)]$ \\
\hline
\end{tabular}




\begin{tabular}{|c|c|c|}
\hline a letter [obj, pat] & $\Rightarrow$ & $\lambda P \lambda e \exists x[P(e) \wedge \operatorname{Pat}(e, x) \wedge$ letter' $(x)]$ \\
\hline a cart [obj, pat] & $\Rightarrow$ & $\lambda P \lambda e \exists x\left[P(e) \wedge \operatorname{Pat}(e, x) \wedge \operatorname{cart}^{\prime}(x)\right]$ \\
\hline [obj, pat] & $\Rightarrow$ & $\lambda P \lambda e \exists x[P(e) \wedge \operatorname{Pat}(e, x) \wedge$ milk' $(x)]$ \\
\hline letters [obj, pat] & $\Rightarrow$ & $\lambda P \lambda e \exists x[P(e) \wedge P a t(e, x) \wedge$ letters' $(x)]$ \\
\hline write a letter & \multicolumn{2}{|c|}{$\lambda \mathrm{e} \exists \mathrm{x}\left[\right.$ write $^{\prime}(\mathrm{e}) \wedge \operatorname{Pat}(\mathrm{e}, \mathrm{x}) \wedge$ letter' $\left.(\mathrm{x})\right]$} \\
\hline Irink milk & \multicolumn{2}{|c|}{$\lambda e \exists x\left[\right.$ drink$^{\prime}(e) \wedge \operatorname{Pat}(e, x) \wedge$ milk' $\left.(x)\right]$} \\
\hline$\Rightarrow$ & \multicolumn{2}{|c|}{$\lambda e \exists x[$ write' $(e) \wedge \operatorname{Pat}(e, x) \wedge$ letters' $(x)]$} \\
\hline$\Rightarrow$ & \multicolumn{2}{|c|}{$\lambda e \exists x\left[\right.$ push' $\left.(e) \wedge \operatorname{Pat}(e, x) \wedge \operatorname{cart}^{\prime}(x)\right]$} \\
\hline
\end{tabular}

The different behavior of predicates like "write a letter," "drink milk," "write letters" and "push a cart" with respect to durational adverbs is expected once we assume that the predicates of the translation language meet the following properties (we differ from Krifka in stating mapping to objects only for non-iterative predicates):

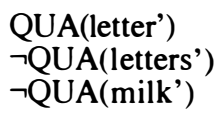

Mapping to Objects for non iterative predicates (applied to drink' and write'):

$\forall \mathrm{e} \forall \mathrm{e}^{\prime} \forall \mathrm{x}\left[\left(\right.\right.$ write' $\left.(\mathrm{e}) \wedge \operatorname{Pat}(\mathrm{e}, \mathrm{x}) \wedge \mathrm{e}^{\prime} \subset \mathrm{e}\right) \rightarrow \exists \mathrm{x}^{\prime}\left[\mathrm{x}^{\prime} \subset \mathrm{x} \wedge\right.$ Pat $\left.\left.\left(\mathrm{e}^{\prime}, \mathrm{x}^{\prime}\right)\right]\right]$

$\forall e^{\prime} \forall e^{\prime} \forall x\left[\left(\right.\right.$ drink $\left.\left.^{\prime}(e) \wedge \operatorname{Pat}(e, x) \wedge e^{\prime} \subset e\right) \rightarrow \exists x^{\prime}\left[x^{\prime} \subset x \wedge P a t\left(e^{\prime}, x^{\prime}\right)\right]\right]$

IIf $x$ is the patient of a writing/drinking event $e$ and $e '$ is a proper subpart of $\mathrm{e}$, there is a proper subpart of $\mathrm{x}$ that is the patient of $\left.\mathrm{e}^{\prime}\right]$

\section{Uniqueness of Objects (applied to drink' and write ):}

$\forall \mathrm{e} \forall \mathrm{x} \forall \mathrm{x}^{\prime} \mid\left(\right.$ write $\left.^{*}(\mathrm{e}) \wedge \operatorname{Pat}(\mathrm{e}, \mathrm{x}) \wedge \operatorname{Pat}\left(\mathrm{e}, \mathrm{x}^{\prime}\right)\right) \rightarrow \mathrm{x}=\mathrm{x}^{\prime} \mid$

$\forall \mathrm{e} \forall \mathrm{x} \forall \mathrm{x}^{\prime}\left[\left(\right.\right.$ drink$\left.^{\prime}{ }^{\prime}(\mathrm{e}) \wedge \operatorname{Pat}(\mathrm{e}, \mathrm{x}) \wedge \operatorname{Pat}\left(\mathrm{e}, \mathrm{x}^{\prime}\right)\right) \rightarrow \mathrm{x}=\mathrm{x}^{\prime} \mid$

IIf $x$ is the patient of a writing/drinking event $e$ and so is $x^{\circ}, x$ is the same as $\mathrm{x}^{\prime} \mathrm{x}$

An immediate consequence of these assumptions is this:

C1.

The predicate write a letter is quantized.

To see why this consequence holds, consider the following reasoning. If write $a$ letter is not quantized, there are two events $\mathrm{e}$ and $\mathrm{e}^{\cdot}$ that are both in the denotation of this predicate and $\mathrm{e}^{\circ} \subset \mathrm{e}$. Since $\mathrm{e}$ and $\mathrm{e}^{\cdot}$ are in the denotation of write a letter, there is an $x$ that is a letter|i.e., is in the denotation of letter ${ }^{\circ}$ and $e$ is a writing event that has $x$ as a patient and there is a $y$ that is a letter and $e^{\prime}$ is a writing event that has $y$ as a patient. As the patient rolc of write has the property of mapping to objects and $\mathrm{e}^{\circ} \subset \mathrm{e}$, there must be an $\mathrm{x}^{{ }^{\prime}}$ such that $\mathrm{x}^{\circ} \subset \mathrm{x}$ and $\operatorname{Pat}\left(\mathrm{e}^{\circ}, \mathrm{x}^{\circ}\right)$. Given that it is not possible for the same writing event to have two different patients (uniqueness of objects), $x^{\prime}=y$. Thus, $y$ is a letter and $x$ is a letter and $y \subset x$. But this contradicts the hypothesis that letter is quantized. 
In other words, given that "write" meets both uniqueness of objects and mapping to objects, if $\mathrm{e}$ is an event of writing a letter, a proper subpart of e must be an event of writing part of a letter. As letter' is quantized, a letter part can't be a letter. So, no proper subpart of an event of writing a letter can be an event of writing a letter. Thus, "write a letter" is quantized. More generally, assuming that count nouns are quantized, Krifka can prove consequence C2 [by Th. 10, Krifka (1992)]:

C2. A non-iterative event predicate $\mathrm{V}$ whose object role $\mathrm{R}$ has the properties of mapping to objects and uniqueness of objects yields a quantized predicate when combined with an object of the form $a(n) N$.

Notice that in this theory, predicates like "write letters" and "push a cart" are not predicted to be quantized, which leads us to expect that they should be able to occur with for-adverbs. The reason why "write letters" doesn't turn out to be quantized is that the predicate letters' is not quantized, and thus a proper subpart of an event of writing letters may still be an event of writing letters. The reason why "push a cart" is not predicted to be quantized is that "push" lacks mapping to objects for noniterative predicates (a proper subpart of an event of pushing a cart may still be an event of pushing the whole cart).

\section{Some Problems for Krifka}

\subsection{The Puzzle of Twigs, Sequences and Quantities of Milk}

Krifka's assumption that count nouns are quantized, on which the previous theorem is based, is problematic with nominal predicates like sequence, twig and quantity' of milk. This fact was originally pointed out by B. Partee (p.c. to Krifka) and by Mittwoch (1988: fn. 24). For example, the sequence of numbers $1,2,3,4,5$ is a proper subpart of the sequence of numbers 1,2.3.4.5.6.7.8.9.10. Thus $1,2.3,4,5,6,7,8,9,10$ is a sequence that has a proper subpart which is also a sequence. A similar case can be constructed for the NPs a twig and a quantity of milk: if $\mathrm{x}$ is a twig. $\mathrm{x}$ may have a proper subpart which is also a twig and if $\mathrm{x}$ is a quantity of milk. $x$ may have a proper subpart which is also a quantity of milk. Thus, the NPs a sequence, a twig and a quantity of milk should not introduce quantized predicates in the logical representation. Yet, the predicates write $a$ sequence, find a twig and drink a quantity of milk are no better than write a letter with for-adverbs:

b. ?? John wrote a letter for an hour

$?$ John wrote a sequence for ten minutes

?? John found a twig for ten minutes

?? John drank a quantity of milk for an hour

\subsection{The Material Part Approach}

In his (1989) paper, Krifka sketches a solution to this puzzle based on Link's ( 1983 ) idea that in the domain of objects we must distinguish between the domain of individuals and the domain of quantities of matter that make up these individuals. This distinction is independently motivated by the following type of reasoning. Brancusi's egg is a marble sculpture Brancusi did in 1924. If this egg and the marble of which it is made are the same thing, we should expect (6) to be a contradiction, as it is impossible for the samc thing to be both $\mathrm{P}$ and not-P. On the 
other hand, if the egg and the marble are distinct entities, the fact that (6) is noncontradictory is expected.

Brancusi's egg came into existence in 1924, but the marble of which the egg is made didn't come into existence in 1924.

The distinction between individuals and quantities of matter comes with a distinction between two part-of relations: the part-of relation between individuals $\subseteq$ I and the part relation between quantities of matter $\subseteq \mathrm{Q}$. Moreover, individuals and quantities of matter are related in Link's theory by a function $h$ that associates to each individual the quantity of matter that makes it up. Having introduced these distinctions, we may restate the notion quantized predicate in this way:

$\forall \mathrm{P}[\mathrm{QUA}(\mathrm{P}) \leftrightarrow \forall \mathrm{x} \forall \mathrm{y}[(\mathrm{x} \in \mathrm{I} \wedge(\mathrm{P}(\mathrm{x}) \wedge \mathrm{P}(\mathrm{y})) \rightarrow \neg \mathrm{y} \subset \mathrm{Ix})]]$

[a predicate $P$ has quantized reference iff $P$ is a predicate of individuals and no P-object can be a proper individual subpart of a P-object]

We may now claim that the predicate is a sequence is quantized in the sense that, if $\mathrm{x}$ is a sequence, no $\mathrm{y} \subset_{\mathrm{I}} \mathrm{x}$ is a sequence (i.e., no individual subpart of $\mathrm{x}$ is itself a sequence). However, a sequence may have other sequences as proper subparts in the sense that it may happen that $x$ is a sequence, $y$ is a sequence and $h(y) \subset_{Q}(x)$ (i.e., the matter that makes up $y$ is part, relative to the part-of relation between quantities of matter, of the matter that makes up $\mathrm{x}$ ). The same solution may also apply to the nominal predicates twig and quantity of milk.

Krifka's way out allows us to keep the view that is a sequence, is a twig and is a quantity of milk are quantized, while allowing for a sense in which a sequence, a twig and a quantity of milk may have proper subparts that are also sequences, twigs and quantities of milk. But, as White (1994) has observed, this solution to the sequence problem leaves a question open. How do we make justice to the intuition that events of writing a sequence, finding a twig, drinking a quantity of milk may have proper subparts that are also events of writing a sequence, finding a twig and drinking a quantity of milk? Suppose John drank a quantity of milk, let's call this event $e$. The first half of the quantity of milk he drank is also a quantity of milk. Let $e^{\prime}$ be the part of $e$ in which John drinks the first half of the quantity of milk. Then, $e$ and $e^{\prime}$ stand in the proper subpart relation and they are both events of drinking a quantity of milk. If this is true, however, the predicate "drink a quantity of milk" is not quantized. Yet, it's unacceptable with for-adverbs.

\subsection{The Hard Line Approach}

A more radical reaction to the puzzle of the twigs is this: we should simply give up the assumption that sequences, twigs and quantities of milk may have proper subparts (individual or material) that are sequences, twigs and quantities of milk. As this view seems to avoid the problem at the cost of giving up a natural intuition, it must be supported with some argument showing that this intuition should be abandoned. One such argument was suggested by M. Krifka at this conference.

Suppose a student is given a test and that this test requires that he write a sequence with a certain property $P$. For example, the test might require the student to write a sequence of prime numbers. Now, suppose that the student writes a sequence $s$ which lacks $P$, although a proper subpart of $s$ meets $P$. For example, he writes $2,3,5,7,10,11$ which is not a sequence of prime numbers, although it 
contains the sequence of prime numbers $2,3,5,7$ as a proper subpart. In this case, the instructor will conclude that the student did not pass the test and will give him an F. This shows that the proper subparts of a sequence are not themselves sequences, otherwise the student could claim that he passed the test because a subpart of $s$ meets $P$.

Notice that the way out of the sequence puzzle this example suggests is different from the one proposed in the material part approach. That approach does not dispute that the first four numbers of a sequence of six numbers may also be a sequence. It denies instead that the first four numbers are an individual subpart of the sequence of six numbers (it claims that they are a material subpart). This is compatible with assuming that the first four numbers are also a sequence. ${ }^{1}$ The example considered here, on the other hand, calls into question the idea that a proper subpart of a sequence (however we understand the notion subpart) can be itself a sequence.

While we agree with the instructor that the student failed the test in the case described above, we think, however, that the argument fails to establish that the proper subparts of a sequence can't be themselves sequences. Even if the sequence the student writes as an answer to the test consists of smaller sequences, there are perfectly good reasons for the instructor to disregard these subsequences in evaluating the answer. In order to make sure that the student does not give the right answer accidentally, a test of this type presupposes that there is a convention by which we can single out the sequence the student means as the answer to the test. A reasonable convention in this case is that the sequence meant as an answer is the maximal sequence that the student writes. This convention is reasonable, since it assumes that the student will not give irrelevant information in answering the test; after all, any convention that singles out the relevant sequence as a subsequence of the sequence written by the student would assume that the student will give irrelevant information in answering the test. So, the assumption that the sequence the student writes consists of smaller sequences is consistent with the behavior of the instructor. In other words, a theory that takes seriously the intuition that an event of writing a sequence may have proper subparts that are also events of writing a sequence can also account for the intuition that the student failed the test. We conclude that Krifka's example fails to support the hard line view.

\subsection{The Puzile of Some}

Another problem for Krifka is posed by contrast (7)-(8):
a. ?? John found some fleas on his dog for an hour
b. John found some fleas on his dog in an hour John found fleas on his dog for an hour

Intuitively, an event of finding some fleas may have proper subparts that are events of finding some fleas. Suppose, for example, that John finds ten fleas one after the other. The event of finding these ten fleas is an event of finding some fleas that has other events of finding some fleas as proper subparts. Yet, (7a) contrasts in acceptability with (8). According to Krifka, NPs like a flea introduce quantized predicates in the translation, since the predicate flea' is assumed to apply to individuals that consist of just one flea. However, it's implausible to assume that some fleas fixes the cardinality of the plural individuals that occur in the denotation of fleas. So, how does Krifka account for contrast (7)-(8)? 


\section{Looking for a Solution}

\subsection{First Try: a Scope Account}

In view of these problems, it seems that the claim that NPs of the form "an N" or "some N" always introduce quantized predicates in the logical representation should be given up. But then, why are (1b), (3) and (7a) awkward? One possible reason is that for-adverbs are forced to take narrow scope with respect to the quantifier binding the object variable. In this case, the event predicates to which the foradverb applies in (1b), (3) and (7a) are predicates of forms (i)-(ii):

(1) b. ?? John wrote a letter for an hour

(3) ?? John wrote a sequence for ten minutes

(7) a. ?? John found some fleas on his dog for an hour

(i) $\quad \lambda e\left[w r i t e^{\prime}(e) \wedge \operatorname{Pat}(e, x)\right]$

(ii) $\quad \lambda e[$ find'(e) $\wedge \operatorname{Pat}(e, x)]$

While an event of writing a sequence, unlike an event of writing a letter, may have an event of writing a sequence as a proper subpart, no proper subpart of an event of writing a particular object $x$, be it a sequence or a letter, can be an event of writing $x$. Assuming that the definition of quantized predicate requires to keep the assignment fixed and that for-adverbs require the predicates they combine with to be non-quantized in this sense, this leads us to expect that (1b), (3) and (7a) should be anomalous. The required definition of quantized predicate may be stated in this way:

(Q) QUA(P) iff for every model $\mathrm{M}$, assignment $\mathrm{g}$, and individual a, b, if $\llbracket P \rrbracket_{M, g}(a)=1$ and $\llbracket P \rrbracket_{M, g}(b)=1$, then a is not a proper subpart of $b$.

In (2c), on the other hand, the for-adverb applies to a predicate of form (iii), where the patient of the event is a kind, as proposed in Carlson (1977):

c. John wrote letters for an hour

$$
\lambda e \mid \text { write' }(e) \wedge \text { Pat (lettersK, e })]
$$

We predict that $(2 \mathrm{c})$ should be acceptable once we assume that the lexical entry of write includes principle $\mathrm{Pl}$ below. This assumption also leads us to expect contrast (9), as the object NP in (9a), unlike the object NPs in (9b-c), lacks a kind reading:

Pl. QUA( $(\lambda e|w r i t e(e) \wedge \operatorname{Pat}(\tau, e)|)$, if the term $\tau$ denotes an object, but not if $\tau$ denotes a kind.

(9) a. * John drank the whole bottle of beer for ten minutes

b. John drank the beer that Bill recommended for hours (before admitting that he hated it).

c. Bill sold this *(type of) vase for years (Verkuyl, 1993)

\subsection{Problems with the First Try}

Rather than elaborating the first try further, we immediately point out some serious problems for it. On the one hand, this try raises the question: why should forradverbs always take narrow scope with respect to quantifiers? While this question 
doesn't show that the first try is wrong, it certainly calls for an answer. The main problem with this try, however, is that quantifiers do occur in the scope of foradverbs. Consider sentence (10a):

\section{a. John wrote no letters for a year}

If no letters in (10a) must take wide scope with respect to the for-adverb, (10a) should only have the following anomalous reading: no letters are such that John wrote them for a year. In fact, (10a) is acceptable and means that at no time during a year period John wrote letters.

The sentences in (11) provide evidence that indefinites must also be allowed in the scope of for-adverbs:

a. John pushed a cart every day for a year

b. John found a flea on his dog every day for a year

Sentence (11a) allows for a reading according to which for every day, there is a cart John pushed that day (possibly, a different cart each day) and this daily pushing went on for a year. However, if indefinite NPs must take wide scope with respect to for-adverbs, we should only expect a reading that says that John pushed the same cart every day for a year.

\subsection{Second Try: a DRT Account}

Facts (10)-(11) show that quantifiers and indefinite NPs are allowed in the scope of for-adverbs. But, if the predicate write a sequence can be translated as in (i'), we are back to the sequence problem.

$$
\text { write a sequence } \quad \Rightarrow \quad \lambda e \exists x \mid \text { write }^{\prime}(e) \wedge \operatorname{Pat}(e, x) \wedge \text { sequence }^{\prime}(x) \mid
$$

If the existential quantifier introduced by the indefinite a sequence is outside the scope of the for-adverb, then the predicate to which the for-adverb applies is (i) and (i) can be plausibly assumed to be quantized once we require that the variable assignment be kept fixed in checking for quantization.

$$
\text { write a sequence } \quad \Rightarrow \quad \lambda \mathrm{e} \mid \text { write' }^{\prime}(\mathrm{e}) \wedge \operatorname{Pat}(\mathrm{e}, \mathrm{x}) \mid
$$

However, the presence of the existential quantifier in translation (i') prevents us precisely from keeping the sequence fixed in checking whether write a sequence is quantized. Even if we assume the definition of quantized predicate in (Q), the result of allowing translation ( $\left.i^{*}\right)$ is that write a sequence is not quantized. Indeed, if $\mathbf{e}$ is an event of writing 1,2,3,4,5 and $\mathbf{e}^{\prime}$ is the subpart of $\mathbf{e}$ in which the sequence 1,2.3 is written, then $\llbracket \lambda e^{\prime} \exists x \mid$ write' $(e) \wedge \operatorname{Pat}(e, x) \wedge$ sequence' $^{\prime}(x) \| \rrbracket M, g(e)=1$ and $\llbracket \lambda e^{\exists} \mid$ write $^{\prime}(e) \wedge \operatorname{Pat}(e, x) \wedge$ sequence $^{*}(x) \rrbracket_{M}, g^{\prime}\left(e^{\prime}\right)=1$, and $\mathbf{e}^{\prime}$ is a proper subpart of e.

A way out of this dilemma is possible if we shift to a DRT-account of the semantics of indefinite NPs. According to the analysis of NPs of the form "an N" and "some N" proposed in Heim (1982) and Kamp (1981), these NPs do not have inherent existential force, they introduce free variables in the translation language and these variables get bound via closure rules. This approach to the semantics of indefinites naturally predicts the fact that (3)-(5) are odd, while allowing for the relative scope of NPs and for-adverbs to be free. We can illustrate how this works 
by assuming the translation rules below, which reflect the view that "an $\mathrm{N}$ " and "some N" are not inherently quantificational (we are departing from Krifka in assuming that verbs denote relations between events and individuals). It should be emphasized that, while these rules allow us to describe this approach by staying close to Krifka's notation, the same story can be told in compositional implementations of DRT, like, for example, those proposed in Asher (1993) and Muskens (1996). ${ }^{2}$

$\begin{array}{llll}\mathrm{T}_{\text {an. }} & {\left[\mathrm{NP} \mathrm{a}(\mathrm{n})\left[\mathrm{N}^{\prime} \alpha\right]\right]} & \Rightarrow & \lambda \mathrm{P} \lambda \mathrm{e}\left[\mathrm{P}(\mathrm{z})(\mathrm{e}) \wedge \alpha^{\prime}(\mathrm{z})\right] \\ \mathrm{T}_{\text {somepl. }} & {\left[\mathrm{NP} \text { somepl }\left[\mathrm{N}^{\prime} \alpha\right]\right]} & \Rightarrow & \lambda \mathrm{P} \lambda \mathrm{e}\left[\mathrm{P}(\mathrm{Z})(\mathrm{e}) \wedge \alpha^{\prime}(\mathrm{Z})\right]\end{array}$

Example:

sequence $\quad \Rightarrow \quad \lambda x\left[\right.$ sequence' $\left.^{\prime}(x)\right]$

[NP a sequence] $\quad \Rightarrow \quad \lambda P \lambda e[P(z)(e) \wedge$ sequence' $(\mathrm{z})] \quad$ by $\mathrm{T}_{\text {an }}$

$\mathrm{T}_{\mathrm{VP}[\mathrm{tr} .]} \quad[\mathrm{VP}[\mathrm{V} \alpha][\mathrm{NP} \beta]] \quad \Rightarrow \quad \lambda \mathrm{y}\left[\beta^{\prime}\left(\lambda \mathrm{x}\left[\alpha^{\prime}(\mathrm{x})(\mathrm{y})\right]\right)\right]$

Example:

write $\quad \Rightarrow \quad \lambda x \lambda y \lambda e\left[w\right.$ rite $\left.^{\prime}(e) \wedge \operatorname{Ag}(e, y) \wedge \operatorname{Pat}(e, x)\right]$

find $\quad \Rightarrow \quad \lambda x \lambda y \lambda e\left[\right.$ find $\left.^{\prime}(e) \wedge A g(e, y) \wedge \operatorname{Pat}(e, x)\right]$

drinkV $\quad \Rightarrow \quad \lambda x \lambda y \lambda e\left[\right.$ drink' $\left.^{\prime}(e) \wedge A g(e, y) \wedge \operatorname{Pat}(e, x)\right]$

$\left[v P\right.$ write a sequence] $\Rightarrow \lambda y \lambda e\left[w_{r i t e}(e) \wedge A g(e, y) \wedge \operatorname{Pat}(e, z) \wedge\right.$ sequence'( $z)]$ by TVP[tr.]

Derivation:

[vP write a sequence $] \Rightarrow \lambda y\left[\lambda P \lambda_{e}\left[\mathrm{P}(\mathrm{z})(\mathrm{e}) \wedge\right.\right.$ sequence' $\left.^{\prime}(\mathrm{z})\right](\lambda x[\lambda x \lambda y \lambda \mathrm{ye}$ $\left.\left.\left.\left[w r_{i t e}^{\prime}(e) \wedge \mathrm{Ag}(e, y) \wedge P a t(e, x)\right](x)(y)\right]\right)\right] \quad$ by TVP|tr.]

$\Rightarrow \lambda y\left[\lambda P \lambda e[P(z)(e) \wedge\right.$ sequence' $\left.(z)]\left(\lambda x \lambda e\left[w_{\text {rite }}(e) \wedge A g(e, y) \wedge P a t(e, x)\right]\right)\right]$ by $\lambda$ - conv.

$\Rightarrow \lambda y\left[\lambda e\left[\lambda x \lambda e \mid w_{\text {rite }}^{\prime}(e) \wedge A g(e, y) \wedge \operatorname{Pat}(e, x)\right](z)(e) \wedge\right.$ sequence' $\left.^{\prime}(z)\right] \mid$ by

$\lambda$ - conv.

$\Rightarrow \lambda y \lambda e \mid w_{\text {rite }}(e) \wedge A g(e, y) \wedge P a t(e, z) \wedge$ sequence' $(z) \mid$ by $\lambda$ - conv.

The sentence John write a sequence is thus translated in this way:

Is John write a sequence $|\Rightarrow \lambda e|$ write $^{\prime}(e) \wedge \mathrm{Ag}\left(e, J o h n{ }^{\prime}\right) \wedge \mathrm{Pat}(\mathrm{e}, \mathrm{z}) \wedge$ sequence'(z)|

Let's assume that phrases like an hour denote properties of intervals and $\tau$ denotes a function that assigns to each event e the interval e takes up. The translation rule for (S-level) for-adverbs may now be stated as follows:

$$
\text { for } \alpha \Rightarrow \lambda \mathrm{P} \lambda \mathrm{e}\left[\mathrm{P}(\mathrm{e}) \wedge \alpha^{\prime}(\tau(\mathrm{e}))\right] / \neg \mathrm{QUA}(\mathrm{P})
$$


The well-formedness condition after / indicates that the function denoted by the foradverb applies only to non-quantized event predicates. The result of combining the for-adverb with the translation of John write a sequence is now this:

$$
\begin{aligned}
& {\left[s \text { John write a sequence for an hour] } \Rightarrow \lambda e \left[\text { write }^{\prime}(e) \wedge A g(e, J o h n ') \wedge\right.\right.} \\
& \operatorname{Pat}(e, z) \wedge \text { sequence' }(z) \wedge 1 \text {-hour }(\tau(e))]
\end{aligned}
$$

Finally, as a consequence of applying existential closure, we get the following translation:

John write a sequence for an hour $\Rightarrow \exists z, e[w r i t e '(e) \wedge \operatorname{Ag}(e, J o h n ') \wedge$ $\operatorname{Pat}(e, z) \wedge$ sequence' $(z) \wedge 1$-hour $(\tau(e))]$

The penultimate step in this derivation is the illegitimate one. Given the definition of quantized predicate in $(\mathrm{Q})$, the event predicate to which the for-adverb applies in this step is quantized, thus the for-adverb should not be able to combine with it.

On the other hand, the following translation rules for the bare plural NP letters and the mass NP milk together with lexical principle P1 predict that no such problem should arise in the derivation of John wrote letters for an hour and John drank milk for an hour:

$$
\begin{array}{lll}
{[\mathrm{NP} \text { milk }]} & \Rightarrow & \lambda P \lambda_{\mathrm{e}}[\mathrm{P}(\mathrm{e})(\mathrm{milkk})] \\
{[\mathrm{NP} \text { letters }]} & \Rightarrow & \lambda P \lambda_{\mathrm{e}}[\mathrm{P}(\mathrm{e})(\text { lettersk)] }
\end{array}
$$

Notice, by the way, that this analysis of the sequence problem also allows us to characterize a sense in which write a sequence is not a quantized predicate. The relevant notion of quantization in this case can be defined as in (KQ):

(KQ) K-QUA(P) iff for every model $\mathrm{M}$, assignment $\mathrm{g}$, $\mathrm{g}$ ' and individual a,b, if $\llbracket P \rrbracket_{M}, g(a)=1$ and $\llbracket P \rrbracket_{M}, g^{\prime}(b)=1$, then $a$ is not a proper subpart of $b$.

According to this definition, the predicate is an event of John's writing a sequence is not $\mathrm{K}$-quantized, since an event of writing a sequence may have an event of writing another sequence as a proper subpart. This is irrelevant for the purpose of combining this predicate with for-adverbs, as these adverbs are sensitive to whether the predicate is quantized and not to whether the predicate is K-quantized.

\subsection{The Case of No}

In discussing the first try, we saw that the quantifier no can occur in the scope of for-adverbs and has the effect of licensing the occurrence of for-adverbs with accomplishment/achievement predicates:

a. John wrote no letters for a year

Krifka (1989) does not provide an account of no, but his analysis of negation can be adapted to this quantifier to provide an account of (10a). Krifka defines the notions maximal event and maximal event at a time $t$ in this way:

$$
\forall \mathrm{e} \forall \mathrm{t} \mid \mathrm{MXT}(\mathrm{e}, \mathrm{t}) \leftrightarrow \mathrm{e}=\mathrm{FU}(\lambda \mathrm{e}|\tau(\mathrm{e}) \subseteq \mathrm{t}|)]
$$


[a maximal event at a time $t$ is the fusion of all events that occur at subintervals of $t]$

$\forall \mathrm{e} \forall \mathrm{t}[\mathrm{MXE}(\mathrm{e}) \leftrightarrow \exists \mathrm{t}[\mathrm{e}=\mathrm{FU}(\lambda \mathrm{e}[\tau(\mathrm{e}) \subseteq \mathrm{t}])]]$

[a maximal event is the fusion of all events that occur at subintervals of some interval]

Negation is then translated as follows:

$$
\text { do not } \Rightarrow \lambda P \lambda \mathrm{e}\left[\mathrm{MXE}(\mathrm{e}) \wedge \neg \exists \mathrm{e}^{\prime}\left[\mathrm{P}\left(\mathrm{e}^{\prime}\right) \wedge \mathrm{e}^{\prime} \subseteq \mathrm{e}\right]\right]
$$

John did not arrive (ignoring tense) $\Rightarrow \lambda \mathrm{e}\left[\mathrm{MXE}(\mathrm{e}) \wedge \neg \exists \mathrm{e}^{\prime}[\right.$ arrive'(e')^ $\left.\left.\operatorname{Ag}\left(e^{\prime} j\right) \wedge e^{\prime} \subseteq e\right]\right]$

[an event of John's not arriving is an e such that, for some time $t, e$ is the fusion of all events that occur at subintervals of $t$ and $e$ does not contain an event of John's arriving as a part]

A consequence of this way of translating negation is that negated event predicates are not quantized and thus for-adverbs are correctly licensed with them:

b. ?? John arrived for three hours

c. John did not arrive for three hours

Intuitively, the reason why this consequence holds is that, if $\mathrm{e}$ is the fusion of all events temporally included in some interval and e does not contain any event of John's arriving, any proper subpart of e which is the fusion of all events temporally included in a subinterval of the interval at which e occurs will also fail to include events of John's arriving.

A similar analysis may be extended to the quantifier no to insure that write no letters is not quantized:

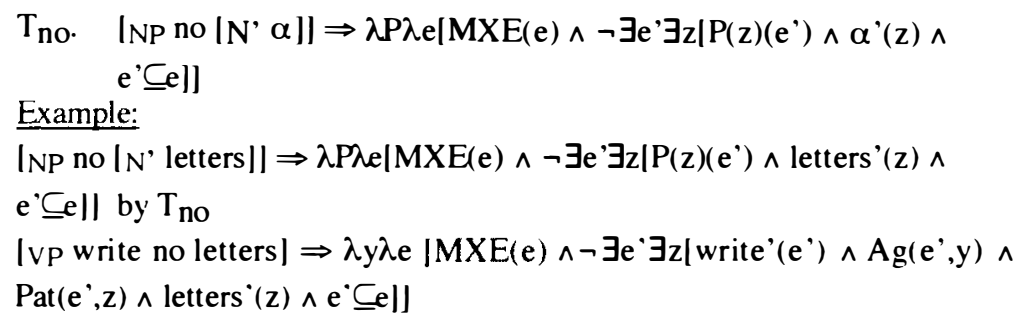

This translation predicts correctly that for-adverbs should be acceptable with the predicate write no letters, since, when the quantified NP no letters is in the scope of the for-adverb, the predicate to which the adverb applies is not quantized.

\subsection{The Problem of Most}

The DRT account suggested here for the sequence problem has nothing to say about why a quantifier like most yields a quantized predicate when it combines with accomplishment/achievement verbs:

(12) a. ?? John found most of the fleas for an hour

b. John found most of the fleas in an hour ${ }^{3}$ 
As NPs like most fleas are inherently quantificational in DRT, they do not introduce free variables, thus we cannot extend to (12) the account suggested for (3)-(5). But then, why is $(12 \mathrm{a})$ odd?

Krifka (1989) proposes the following analysis of most:

the function max maps a relation between numbers and entities to the highest number for which the relation holds

$$
\begin{aligned}
& \text { most fleas[obj, pat }] \Rightarrow \lambda P \lambda e\left[M X E ( e ) \wedge \operatorname { m a x } \left(\lambda n \lambda x \exists e ^ { \prime } \left[P\left(e^{\prime}\right) \wedge \text { flea' }(x, n) \wedge\right.\right.\right. \\
& \left.\left.\operatorname{Pat}\left(x, e^{\prime}\right) \wedge e^{\prime} \subseteq \text { e] }\right)>1 / 2 \max (\lambda n \lambda x[\text { flea' }(x, n)])\right] \\
& \text { find most fleas } \Rightarrow \lambda e\left[M X E ( e ) \wedge \operatorname { m a x } \left(\lambda n \lambda x \exists e ^ { \prime } \left[f_{i n d}^{\prime}\left(e^{\prime}\right) \wedge \text { flea' }(x, n) \wedge\right.\right.\right. \\
& \left.\left.\left.\operatorname{Pat}\left(x, e^{\prime}\right) \wedge e^{\prime} \subseteq e\right]\right)>1 / 2 \max (\lambda n \lambda x[\text { flea' }(x, n)])\right]
\end{aligned}
$$

According to this translation, an event $e$ is an event of finding most fleas iff e meets these conditions:

(i) e is the fusion of all events included in some interval;

(ii) the number of found fleas in $\mathrm{e}$ is greater than a half of the number of fleas.

The problem with this analysis is that it fails to predict that the find most fleas is quantized. Suppose that there are only ten fleas and that during the interval i John found nine fleas, while during the interval $i$ ' $\subset i$ he found seven fleas. Now, consider the fusion e of all events temporally included in $i$ and the fusion $e$ ' of all events temporally included in i'. Presumably, e' $\subset$ e. But in both e and e' the number of found fleas is greater than a half of the number of fleas. Thus, both $e$ and $\mathrm{e}^{\prime}$ are in the denotation of find most fleas. Thus, Krifka's interpretation of most does not guarantee that find most fleas is quantized. Yet, $(12 \mathrm{a})$ is anomalous (barring it erative readings).

M. Rooth observed at this conference that the problem raised by most, rather than pointing at an inadequacy of Krifka's translation of most, may indicate instead that the assumption that for-adverbs apply to non-quantized predicates is insufficient to account for their distribution. For example, the problem posed by most for Krifka would disappear if we imposed a stricter condition on the domain of application of for-adverbs:

A2. a predicate $\mathrm{P}$ can combine with for-adverbs iff some event in the denotation of $\mathrm{P}$ is the sum of two disjoint events that are also in the denotation of $\mathrm{P}$.

As no event of finding most fleas can be the sum of two disjoint events of finding most fleas, the predicate find most fleas is correctly predicted to be unacceptable with $f(r-$-adverbs by this condition. However, notice that, while restating the condition on the domain of applicability of for-adverbs may help in accounting for the behavior of certain NP-types, the condition just mentioned, besides failing to account for predicates like write some letters (which seem to meet $\mathrm{A} 2$ and yet are odd with for-adverbs), also fails to account for the bchavior of proportional quantifiers other than most. like for example the quantifier less than half. Indeed, the predicate find less than half of the fleas seems to meet A2, although $(12 \mathrm{c})$ is anomalous:

$$
\text { c. ?? John found less than half of the fleas for an hour }
$$


For this reason, we go on assuming that the problem posed by the behavior of proportional quantifiers with for-adverbs calls for restating the interpretations of these quantifiers rather than the condition on the domain of applicability of foradverbs.

We could make sure that find most fleas is quantized by using Krifka's relation maximal event at a time $t(M X T)$ in place of the relation MXE in the translation of most :

$$
\begin{aligned}
& \text { most fleas[obj, pat }] \Rightarrow \lambda P \lambda e\left[M X T ( e , t ) \wedge \operatorname { m a x } \left(\lambda n \lambda x \exists e ^ { \prime } \left[P\left(e^{\prime}\right) \wedge \text { flea' }(x, n)\right.\right.\right. \\
& \left.\left.\left.\wedge \operatorname{Pat}\left(x, e^{\prime}\right) \wedge e^{\prime} \subseteq e\right]\right)>1 / 2 \max (\lambda n \lambda x[\text { flea' }(x, n)])\right]
\end{aligned}
$$

In this case, find most fleas turns out to be quantized, as no proper subpart of the fusion of all events temporally included in t can also be the fusion of all events temporally included in t. The reason why this won't do, however, is that it predicts that activity predicates should also be quantized when they combine with most. This prediction is incorrect, as the acceptability of (12d) shows:

\section{d. John ruled most of the committees for ten years}

Notice, by the way, that a problem similar to the one described for most arises also for Krifka's translation of quantifiers like less than $n$. His translation for less than ten fleas does not insure that predicates like find less than ten fleas are quantized, while they should be by the for-adverb test:

$$
\begin{aligned}
& \text { less than ten fleas }[\text { obj, pat }] \Rightarrow \lambda \operatorname{P} \lambda \mathrm{e}\left[\mathrm { MXE } ( \mathrm { e } ) \wedge \operatorname { m a x } \left(\lambda \mathrm{n} \lambda \times \exists \mathrm{e}^{\prime} \mid \mathrm{P}\left(\mathrm{e}^{\prime}\right) \wedge\right.\right. \\
& \text { flea' } \left.\left.\left.^{\prime}(\mathrm{x}, \mathrm{n}) \wedge \operatorname{Pat}\left(\mathrm{x}, \mathrm{e}^{\prime}\right) \wedge \mathrm{e}^{\prime} \subseteq \mathrm{e}\right]\right)<10\right]
\end{aligned}
$$

(13) a. ?? John found less than ten fleas for an hour

b. John found less than ten fleas in an hour

\subsection{A Solution to the Problem of Most: Maximal Participants}

An account of the behavior of most with activity predicates and accomplishment/ achievement predicates can be obtained by summing individuals instead of summing events. Intuitively, this solution may be stated in this way: an event of John's writing most of the letters is a writing event whose patient is (the plural individual which is) the sum of all the letters written by John at a reference time t and the cardinality of this plural individual must be greater than a half of the number of the letters. To see why this way of handling most yields the desired result, let's see what the translations of most and of the relevant predicates look like in this account. Let's define the relation Max in this way:

$$
\forall x|\operatorname{Max}(P, x) \leftrightarrow \neg \exists y| P(y) \wedge x \subset y||
$$

lan individual is a maximal $\mathrm{P}$ iff $\mathrm{it}$ is not a proper subpart of another $\mathrm{P}$ |

Let's assume that. while the predicate of the translation language letter' contains only atomic letters, the predicate letters contains in its denotation all the objects that are either individual letters or plural individuals obtained by summing these letters:

$$
\text { \letter' } \rrbracket_{M}=\{x \in U \mid x \text { is a letter }\}
$$


【letters' $\rrbracket M=\{x \in U \mid x \in \llbracket$ letter' $\rrbracket M$ or $x$ is the sum of individuals belonging to 【letter' $\rrbracket \mathrm{M}\}$

We can now state the translation of most letters in this way:

$$
\begin{aligned}
& \text { most letters } \Rightarrow \lambda P \lambda e \exists x\left[P ( x ) ( e ) \wedge \operatorname { M a x } \left(\lambda z \exists e ^ { \prime } \left[P(z)\left(e^{\prime}\right) \wedge \text { letters' }(z) \wedge\right.\right.\right. \\
& \left.\left.\left.\tau\left(e^{\prime}\right) \subseteq t\right], x\right) \wedge|x|>1 / 2 \sum\left(\lambda z\left[\operatorname{letter}^{\prime}(z)\right]\right)\right]
\end{aligned}
$$

The predicate write most letters will be thus translated as follows:

$$
\begin{aligned}
& \text { write most letters } \Rightarrow \quad \lambda y \lambda e \exists x\left[w_{r i t e}(e) \wedge \operatorname{Ag}(e, y) \wedge P a t(e, x) \wedge\right. \\
& \operatorname{Max}\left(\lambda z \exists e^{\prime}\left[w r i t e^{\prime}\left(e^{\prime}\right) \wedge \operatorname{Ag}\left(e^{\prime}, y\right) \wedge \operatorname{Pat}\left(e^{\prime}, z\right) \wedge \text { letters' }(z) \wedge \tau\left(e^{\prime}\right) \subseteq t\right], x\right) \wedge \\
& \left.|x|>1 / 2 \sum\left(\lambda z\left[l_{\text {letter'}}(\mathrm{z})\right]\right)\right]
\end{aligned}
$$

[an event of writing most of the letters is a writing event whose patient is the sum of all the letters written at the reference time $t$ and the cardinality of this plural individual must be greater than a half of the number of the letters.]

According to this translation, the predicate which results from saturating the subject argument of write most letters is quantized. Here's why. Given that the object role of write has the property of mapping to objects, a proper subpart e' of an event $\mathrm{e}$ in the denotation of write most letters should affect a proper subpart of the sum of all letters written at the reference time $t$. But this means that $e^{\prime}$ is not in the denotation of write most letters, since by definition events in this denotation must have the sum of all letters written at $t$ as patients.

On the other hand the translation of activity predicates like rule most countries will be this:

$$
\begin{aligned}
& \text { rule most countries } \Rightarrow \lambda y \lambda e \exists x \mid \text { rule'(e) } \wedge \mathrm{Ag}(\mathrm{e}, \mathrm{y}) \wedge \mathrm{Pat}(\mathrm{e}, \mathrm{x}) \wedge
\end{aligned}
$$

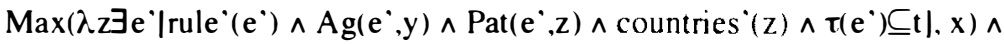

$$
\begin{aligned}
& |x|>1 / 2 \sum(\lambda z \mid \text { country }(z) \mid) \mid
\end{aligned}
$$

The predicate which results from saturating the subject argument of rule most countries is not quantized. Indeed, suppose that $\mathrm{e}$ is an event of ruling most of the countries. Then, $\mathrm{e}$ is an event whose patient is the sum of all the countries ruled at the reference time t. But. as rule doesn't have the property of mapping to objects for non-iterative predicates. the set of countries ruled at $t$ may also be the set of countries ruled during a proper subpart e' of e. This means that both e and e' may be in the denotation of rule most countries. If this is correct, this way of stating the semantics of most achieves the desired result that this quantifier yields quantized predicates when combined with achievement/accomplishment verbs and yields nonquantized predicates when combined with activity verbs.

\section{The Maximal Participant Approach: an Alternative Account?}

In the DRT approach sketched so far, we have accounted for the quantizing power of NPs of the form "an N" by assuming that these NPs are not inherently quantificational and we have accounted for the quantizing power of NPs of the form "most $\mathrm{N}$ " by appealing to maximal participants. While we do not necessarily expect uniformity here, a natural question to ask is whether the maximal participant 
approach provides an alternative strategy for explaining the behavior of quantizing NPs in general. In the remaining part of this paper, we explore this possibility.

By appealing to maximal participants, we can account for the fact that accomplishment/achievement verbs are quantized when they combine with NPs of the form "an N" and "some N" compatibly with the view that these NPs are quantificational (a view which is held, for example, by DMG accounts of anaphora). Applied to NPs of this type, the maximal participant approach amounts to assuming translation rules of the following kind:

$$
\begin{aligned}
& {\left[\mathrm{NP} \text { some }_{\mathrm{pl}}\left[\mathrm{N}^{\prime}, \alpha\right]\right] \Rightarrow \lambda \mathrm{P} \lambda \mathrm{e} \exists \mathrm{x}\left[\mathrm { P } ( \mathrm { x } ) ( \mathrm { e } ) \wedge \operatorname { M a x } \left(\lambda \mathrm { z } \exists \mathrm { e } ^ { \prime } \left[\mathrm{P}(\mathrm{z})\left(\mathrm{e}^{\prime}\right) \wedge \alpha^{\prime}(\mathrm{z}) \wedge\right.\right.\right.} \\
& \left.\left.\left.\tau\left(e^{\prime}\right) \subseteq t\right], x\right) \wedge|x|>1\right] \\
& {\left[\mathrm{NP} a(\mathrm{n})\left[\mathrm{N}^{\prime} \alpha\right]\right] \Rightarrow \lambda \mathrm{P} \lambda \mathrm{e} \exists \mathrm{x}\left[\mathrm { P } ( \mathrm { x } ) ( \mathrm { e } ) \wedge \operatorname { M a x } \left(\lambda \mathrm { z } \exists \mathrm { e } ^ { \prime } \left[\mathrm{P}(\mathrm{z})\left(\mathrm{e}^{\prime}\right) \wedge \alpha^{\prime}(\mathrm{z}) \wedge\right.\right.\right.} \\
& \left.\left.\left.\tau\left(e^{\prime}\right) \subseteq \underline{t}\right], x\right)\right] \\
& \text { some letters } \Rightarrow \lambda P \lambda e \exists x\left[P ( x ) ( e ) \wedge \operatorname { M a x } \left(\lambda z \exists e ^ { \prime } \left[P(z)\left(e^{\prime}\right) \wedge \text { letters' }(z) \wedge\right.\right.\right. \\
& \left.\left.\left.\tau\left(e^{\prime}\right) \subseteq \underline{t}\right], x\right) \wedge|x|>1\right] \\
& \text { a letter } \Rightarrow \lambda \operatorname{P} \lambda e \exists x\left[P(x)(e) \wedge \operatorname{Max}\left(\lambda z \exists e^{\prime}\left[P(z)\left(e^{\prime}\right) \wedge \text { letter' }(z) \wedge \tau\left(e^{\prime}\right) \subseteq \underline{t}\right], x\right)\right]
\end{aligned}
$$

The predicates write a letter and write some letters are thus assigned these translations:

write some letters $\Rightarrow \lambda y \lambda e^{\prime} \exists x[w r i t e(e) \wedge \operatorname{Ag}(y, e) \wedge \operatorname{Pat}(x, e) \wedge$
$\operatorname{Max}\left(\lambda z \exists e^{\prime} \mid w r i t e\left(e^{\prime}\right) \wedge \operatorname{Ag}\left(y, e^{\prime}\right) \wedge \operatorname{Pat}\left(z, e^{\prime}\right) \wedge\right.$ letters $\left.\left.(z) \wedge \tau\left(e^{\prime}\right) \subseteq t\right], x\right) \wedge$
$|x|>1]$
lan event of writing some letters is a writing event whose patient is maximal
among the plural individuals that are letters written at the reference time $t]$

write a letter $\Rightarrow \lambda y \lambda e \exists x \mid w r i t e(e) \wedge A g(y, e) \wedge \operatorname{Pat}(x, e) \wedge$

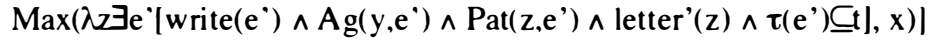

lan event of writing a letter is a writing event whose patient is maximal among the individuals in the denotation of letter written at the time $t]$

Let's consider the case of write some letters first. According to this translation, the predicate is an event of John's writing some letters is quantized for the following reason. Given that letters' is cumulative, there is exactly one element which is maximal in the denotation of the predicate $\lambda z_{\exists} \exists \mathrm{e}^{\prime} \mid w r i t e\left(\mathrm{e}^{\prime}\right) \wedge \mathrm{Ag}\left(\mathrm{J}\right.$ ohn, $\left.\mathrm{e}^{\prime}\right) \wedge$ Pat $\left(z, e^{\prime}\right) \wedge$ letters' $(z) \wedge \tau\left(e^{\prime}\right) \subseteq l$ and this element is the sum of all letters written by John at t. An event of John's writing some letters must thus have as a patient the sum of all letters written by John at the reference time t. As the object role of write has the property of mapping to objects, a proper subevent $e^{\cdot}$ of an event in the denotation of $i$ s an event of John's writing some letters must have as a patient a proper subpart of the sum of all the letters written at t. But this means that $\mathrm{e}^{\prime}$ is not in the denotation of is an event of John's writing some letters.

Now, consider the translation of the predicate write a letter. As the predicate letter' is not cumulative, there may be more than a maximal element in the denotation of $\lambda z \exists \mathrm{e}^{\prime} \mid w$ rite $\left(\mathrm{e}^{\prime}\right) \wedge \mathrm{Ag}(\mathrm{John}, \mathrm{e}) \wedge \operatorname{Pat}(\mathrm{z}, \mathrm{e}) \wedge$ letter' $\left.(\mathrm{z}) \wedge \tau\left(\mathrm{e}^{\prime}\right) \subseteq \mathrm{t}\right]$. In 
particular, any singular letter written by John in the interval t counts as maximal. So, an event of John's writing a letter is an event whose patient is a singular letter written in the interval of reference t. Since the object role of write has the property of mapping to objects, a proper subevent e' of an event in the denotation of is an event of John's writing a letter must have as a patient a proper subpart of a single letter. But a proper subpart of a letter isn't a letter, so e' is not an event of writing a letter.

Notice that this way of stating the semantics of some and an is consistent with the way NPs with these determiners enter in anaphoric relations. Consider discourses (14)-(15):

(14) I have some dimes in my pocket. I'll put them in the meter.

(15) I have a dime in my pocket. I'll put it in the meter.

Discourse (14) says that I'll put in the meter all the dimes I have in my pocket at the time of utterance. Discourse (15), on the other hand, contrasts with discourse (16) below since (15), unlike (16), is compatible with my having more than one dime in my pocket and with my putting in the meter just one of these dimes.

(16) I have one dime in my pocket. I'll put it in the meter

Given the above translations, the facts in (14)-(15) are expected. The patient of the eventuality described by the first sentence in (14) is the sum of all the dimes I have in my pocket, so the pronoun they refers to this sum. On the other hand, although our translation for I have a dime in my pocket is consistent with my having more than one dime in my pocket, according to this translation the patient of the eventuality of my having a dime in my pocket is a single dime in my pocket. Thus, the second sentence in (15) does not require that I put all the dimes I have in the meter. Finally, to get the uniqueness effect in (16), the interpretation of one should be specified as follows:

$$
\begin{aligned}
& \text { INP one }\left[N^{\prime} \alpha\right] \mid \Rightarrow \lambda P \lambda e \exists x\left[P ( x ) ( e ) \wedge \operatorname { M a x } \left(\lambda z \exists e^{\prime} \mid P(z)\left(e^{\prime}\right) \wedge \alpha^{\prime}(z) \wedge\right.\right. \\
& \left.\left.\tau\left(e^{\prime}\right) \subseteq \mathrm{t}\right], \mathrm{x}\right) \wedge \forall \mathrm{r}\left[\operatorname{Max}\left(\lambda z \exists \mathrm{e}^{\prime}\left[\mathrm{P}(\mathrm{z})\left(\mathrm{e}^{\prime}\right) \wedge \alpha^{\prime}(\mathrm{z}) \wedge \tau\left(\mathrm{e}^{\prime}\right) \subseteq \mathrm{t}\right], \mathrm{r}\right) \rightarrow \mathrm{r}=\mathrm{x}\right] \mid \\
& \text { have one dime } \Rightarrow \lambda y \lambda e \exists x \mid \text { have'(e) } \wedge \operatorname{Pat}(e, x) \wedge A g(e, y) \wedge \\
& \operatorname{Max}\left(\lambda z \exists e^{\prime} \mid \text { have } e^{\prime}\left(e^{\prime}\right) \wedge \operatorname{Pat}\left(e^{\prime}, z\right) \wedge \operatorname{Ag}\left(e^{*}, y\right) \wedge \operatorname{dime}^{*}(z) \wedge \tau\left(e^{\prime}\right) \subseteq t \mid, x\right) \wedge \\
& \forall \mathrm{r} \mid \operatorname{Max}\left(\lambda z_{\exists} \mathrm{e}^{\prime} \mid \text { have' }\left(\mathrm{e}^{\prime}\right) \wedge \operatorname{Pat}\left(\mathrm{e}^{\prime}, \mathrm{z}\right) \wedge \operatorname{Ag}\left(\mathrm{e}^{\prime}, \mathrm{y}\right) \wedge \operatorname{dime}^{\prime}(\mathrm{z}) \wedge \tau\left(\mathrm{e}^{\prime}\right) \subseteq \mathrm{t} \mid, \mathrm{r}\right) \rightarrow \\
& r=x \|] \\
& \text { |an event of } y \text { 's having one dime is an event whose patient } x \text { meets (i)-(ii): } \\
& \text { (i) } x \text { is maximal among the patients of an event of } y \text { 's having a dime and (ii) } \\
& \mathrm{x} \text { is the unique individual meeting (i) }
\end{aligned}
$$

The interpretation of the definite article the in this approach will look like this (where $\operatorname{At}(x, t)$ means that $x$ is in existence at $t$ ):

$$
\begin{aligned}
& \mid N P \text { the }\left|N^{\prime} \alpha\right||\Rightarrow \lambda P \lambda e \exists x| P(x)(e) \wedge \operatorname{Max}\left(\lambda z\left|\alpha^{\prime}(z)\right|, x\right) \wedge \forall y \mid \operatorname{Max}\left(\lambda z \mid \alpha^{\prime}(z)\right. \\
& \wedge \operatorname{At}(z, t) \mid, y) \rightarrow x=y \| \\
& \text { find the flea } \Rightarrow \lambda y \lambda e \exists x \mid f i n d '(e) \wedge \operatorname{Pat}(x, e) \wedge \operatorname{Ag}(y, e) \wedge \operatorname{Max}\left(\lambda z\left|f l e a^{\prime}(z)\right|, x\right) \\
& \wedge \forall y\left|\operatorname{Max}\left(\lambda z\left|f l e a^{\prime}(z) \wedge \operatorname{At}(z, t)\right|, y\right) \rightarrow x=y\right| l
\end{aligned}
$$


[an event of finding the flea is a finding event whose patient is the maximal element in the denotation of flea']

find the fleas $\Rightarrow \lambda y \lambda e \exists x[$ find'(e) $\wedge \operatorname{Pat}(x, e) \wedge A g(y, e) \wedge$

$\operatorname{Max}\left(\lambda z\left[\right.\right.$ fleas' $\left.\left.^{\prime}(\mathrm{z})\right], \mathrm{x}\right) \wedge \forall \mathrm{y}\left[\operatorname{Max}\left(\lambda \mathrm{z}\left[\right.\right.\right.$ fleas' $\left.\left.\left.\left.^{\prime}(\mathrm{z}) \wedge \operatorname{At}(\mathrm{z}, \mathrm{t})\right], \mathrm{y}\right) \rightarrow \mathrm{x}=\mathrm{y}\right]\right]$

[an event of finding the fleas is a finding event whose patient is the maximal element in the denotation of fleas']

\subsection{Back to Sequences, Twigs and Quantities of Milk}

How does this account fare with respect to the problem posed by predicates like sequence, twig and quantity of milk? The account correctly predicts that the predicate is an event of John's writing a sequence is quantized.
write a sequence $\Rightarrow \lambda y \lambda e \exists x[w \operatorname{rite}(e) \wedge A g(y, e) \wedge \operatorname{Pat}(x, e) \wedge$ $\operatorname{Max}\left(\lambda z \exists e^{\prime}\left[w r i t e\left(e^{\prime}\right) \wedge A g\left(y, e^{\prime}\right) \wedge \operatorname{Pat}\left(z, e^{\prime}\right) \wedge\right.\right.$ sequence' $\left.\left.\left.(z) \wedge \tau\left(e^{\prime}\right) \subseteq \underline{t}\right], x\right)\right]$ [an event of writing a sequence is a writing event whose patient is maximal among the individuals that are in the denotation of sequence written at the time $t]$

It makes this prediction, since according to the translation of write a sequence, an event of writing a sequence is a writing event whose patient is the maximal sequence written at the reference time t. As the object role of write has the property of mapping to objects, a proper subpart of any such event cannot be an event of writing a maximal sequence written at $t$.
A potential problem for this account is posed by contrast (17)-(18):

(17) I have a quantity of gold in my pocket. I'll put it on the table.

(18) I have one quantity of gold in my pocket. I'll put it on the table.

Discourses (17)-(18) seem to contrast exactly in the way (15)-(16) do. Intuitively. the truth of (17), unlike the truth of (18), is compatible with my having two lumps of gold in my pocket at the time of utterance and with my putting on the table just one of them. What does the maximal participant analysis of the first sentence in (17) say in this case? This analysis says that the patient of the event this sentence describes should be a quantity of gold that is maximal among the quantities of gold I have in my pocket at the time of utterance. But what is a maximal quantity of gold in my pocket at the time of utterance? If the sum of the two lumps in my pocket is a quantity of gold, the analysis requires that, for (17) to be true, I must put both lumps on the table.

If we pursue the maximal participant approach for NPs of the form " an N". the way out of this dilemma lies in assuming that the two lumps of gold I have in my pocket may each count as a maximal quantity of gold in my pocket. This means that it must be possible to restrict the domain of interpretation of NPs like a quantiry. of gold in such a way that, while each of the two lumps of gold in my pocket falls in the denotation of the predicate is a quantity of gold the sum of the two lumps does not. Notice, by the way, that while this move is needed in the maximal participant approach in order to handle cases like (17)-(18), appeal to contextual restrictions of this sort is by itself insufficient to account for (3)-(5):

(3) ? John wrote a sequence for ten minutes

(4) ?? John found a twig for ten minutes 
In order to account for these facts, it's not enough to allow for the possibility that the domain of quantification be contextually restricted in such a way as to disregard proper subsequences of the sequence John wrote, proper subtwigs of the twig John found and proper subquantities of the quantity of milk John drank. We need more: we need to exclude the possibility that these subparts ever count for establishing whether the event predicates in (3)-(5) are quantized. This suggests that a proper account of the facts in (3)-(5) must be found in the semantics of indefinite NPs, rather than in the realm of pragmatics. The maximal participant approach and the DRT approach we presented in this paper explore different hypotheses about what factors in the semantics of these NPs are responsible for (3)-(5).

\section{Summary and plans for the future}

We presented two accounts of the influence of different NP-types on the aspectual class of predicates. The two accounts agree on appealing to maximal participants in analyzing non-cardinal quantifiers like most and less than half, but differ on quantifiers like $a$, some, etc.: the DRT account attributes their quantizing power to their non-quantificational nature, the other account suggests that these NPs also introduce maximal participants.

There are some issues whose discussion would have found a place in this paper, had not been for space limits. We list them here in the form of promissory notes. In observing that indefinites may occur in the scope of for-adverbs, we mentioned (11) as one such case. By Krifka's analysis of for-adverbs, this means that frequency adverbs can combine with quantized event predicates and yield nonquantized event predicates. This result can be achieved by means of the fusion operation employed in the translation of no.

a. John pushed a cart every day for a year

b. John found a flea on his dog every day for a year

In the spatial domain, one finds puzzles similar to the ones we discussed here. Intuitively, the predicate $i$ s an event of running past the hridge doesn't seem to be quantized (as some events of this type may contain proper subparts which are also events of running past the bridge). Yet, sentence (19) is anomalous:

\section{?? John ran past the bridge for an hour}

Again, the accounts sketched here suggest some ways of dealing with this problem. Finally, this paper contains no discussion of alternative approaches to the semantics of for-adverbs. Dowty (1979) and Moltmann (1991) analyze for-adverbs as universal quantifiers over subintervals of measured intervals. Moltmann argues that this is preferable to analyzing for-adverbs as measuring events (as in Krifka's theory). We cannot discuss her arguments here. But the problems we raised for Krifka's theory are also problems for theories that treat for-adverbs as quantifiers over subintervals and the solutions we sketched may be pursued in these theories as well. 


\section{Endnotes}

* We thank Paolo Casalegno, Greg Carlson, Gennaro Chierchia, Graham Katz, Manf red Krifka, Mats Rooth, and the audience of SALT VI for comments.

1. In sketching the material part approach, Krifka (1989:87) says this about twigs (the same observation is meant to apply to sequences): "...consider a twig $x_{1}$ which contains another twig $x_{2}$ as a part. This relation can be captured by claiming that $x_{2}$ is a material subpart of $x_{1}$ and $x_{2}$ is not an individual subpart of $x_{1}$."

2. A Muskens-style version of the DRT account is given in an expanded version of this paper.

3. G. Carlson pointed out to us that there is a contrast between (12b) and (i) (which we had noticed too):

(12)b. John found most of the fleas in an hour

(i) ?? John found most fleas in an hour

We don't know how to account for this fact. As it doesn't seem to affect our argument, we'll ignore it.

\section{References}

Asher N. (1993) Reference to Abstract Objects in Discourse, Kluwer, Dordrecht Carlson G. (1977) Reference to Kinds in English, Ph.D. Dissertation, University of Massachusetts, Amherst, published in 1980 by Garland, New York

Dowty D. (1979) Word Meaning and Montague Grammar, Reidel, Dordrecht

Heim I. (1982) The Semantics of Definite and Indefinite Noun Phrases, Ph.D. dissertation, University of Massachusetts, Amherst, published in 1989 by Garland, New York

Kamp H. (1981) "A Theory of Truth and Semantic Representation," in J. Groenendijk, T. Janssen, and M. Stokhof (eds.), Formal Methods in the Study of Language, MCT, Amsterdam, 277-322 (also in Groenendijk et al. (eds.), Truth. Interpretation and Information, Foris, Dordrecht, 1-41)

Krifka M. (1986) Nominalreferenz und Zeitkonstitution. Zur Semantik von Masstermen, Pluraltermen und Aspektklassen. PhD. Dissertation, Universität München, published in 1989 by Fink Verlag, Münich

Krifka M. (1989) "Nominal Reference, Temporal Constitution and Quantification in Event Semantics“ in R. Bartsch et Al. (eds.) Semantic's and Contextual Expressions, Foris, Dordrecht, 75-115

Krifka M. (1992) "Thematic Relations as Links Between Nominal Reference and Temporal Constitution," in I. A. Sag and A. Szabolcsi (eds.) Lexical Matters. Stanford University, 29-53

Link G. (1983) "The Logical Analysis of Plurals and Mass Terms: a LatticeTheoretic approach," in R. Bäuerle et Al. (eds.) Meaning. Use and Interpretation of Language, Mouton, Berlin, 302-23

Mittwoch A. (1988) "Aspects of English Aspect: on the Interaction of Perfect, Progressive, and Durational Phrases", Linguistics and Philosophy, 11, 203-254

Moltmann F. (1991) "Measure Adverbials" Linguistics and Philosophy, 14, 629660

Muskens R. (1996) "Combining Montague Semantics and Discourse Representation," Linguistic:s and Philosophy, 19, 143-186

Verkuyl H. J. (1993) A Theory of Aspectuality, Cambridge University Press, Cambridge

White M. (1994) A Computational Approach to Aspectual Composition, Ph.D. Dissertation, University of Pennsylvania 